
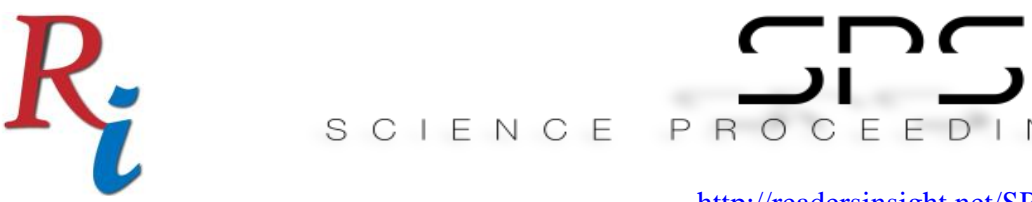

http://readersinsight.net/SPS

\title{
DEVELOPMENT AND CHARACTERIZATION OF SURFACE- MODIFIED NANOPARTICLES USING FLUORINE-BASED CHEMICALS
}

\author{
Kenny Ganie* \\ Department of Petroleum Engineering \\ Universiti Teknologi PETRONAS, Seri Iskandar, Perak, \\ Malaysia \\ Dzeti Farhah Mohshim \\ Department of Petroleum Engineering \\ Universiti Teknologi PETRONAS, Seri Iskandar, Perak, \\ Malaysia

\section{Ismail Mohd Saaid} \\ Department of Petroleum Engineering \\ Universiti Teknologi PETRONAS, Seri Iskandar, Perak, \\ Malaysia

\section{Wan Rosli Wan Sulaiman} \\ Department of Petroleum Engineering \\ Universiti Teknologi Malaysia, Skudai, Johor, \\ Malaysia \\ Ahmad Kamal Idris \\ Department of Petroleum Engineering \\ Universiti Teknologi Malaysia, Skudai, Johor, \\ Malaysia
}

*Corresponding author's Email: kenny 16000607@utp.edu.my

Peer-review under responsibility of 4th Asia International Multidisciplinary Conference 2020 Scientific Committee http://connectingasia.org/scientific-committee/ (C) 2020 Published by Readers Insight Publisher, lat 306 Savoy Residencia, Block 3 F11/1,44000 Islamabad. Pakistan, editor@readersinsight.net This is an open access article under the CC BY-NC-ND license (http://creativecommons.org/licenses/by-nc-nd/4.0/). 

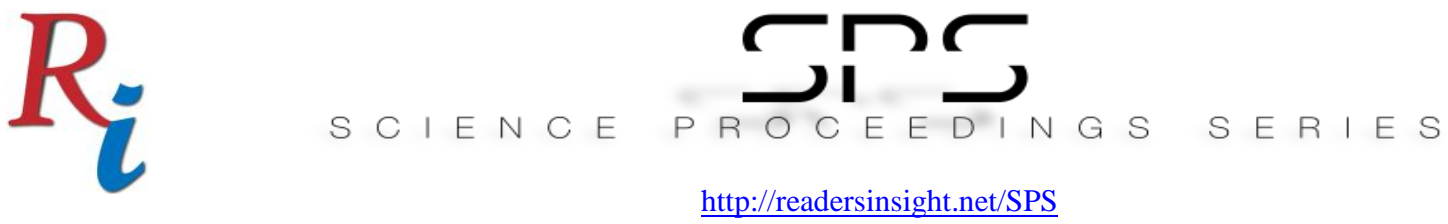

\section{A b s t r a c t}

Scientist have been using chemical treatment to change the wettability of near-wellbore region for condensate banking removal (1-5). However, this technique performed unsatisfactorily as the chemical treatment only reduce the surface energy without modifying the surface roughness and negatively affects the gas relative permeability (6). Hence, in the present study, an alternative surface-modified nanoparticle using fluorine-based chemicals was developed as a new wettability alteration agent since fluorine exhibits high degree of water and oil repellency (7). The new wettability alteration agent was evaluated based on FTIR, DLS and TGA characterization. The results show that the surface of nanoparticles has been modified with fluorine-based chemicals coating and this is proven from: FTIR spectra with new peaks observed; DLS characterization with incremental size of surface-modified nanoparticles; and TGA with decomposition rate of coating agents. Implications of the results will path the way for future research direction in using fluorine surface modified nanoparticles as a wettability alteration agent.

Keywords: Nanoparticles, Surface Modified, Fluorine, Fluoroalkanoic Acid

\section{Research High I ight s}

1. Nanosilica surface is successfully functionalized with fluoroalkanoic acid.

2. FTIR, DLS and TGA characterization confirmed the success of fluorine-surfacemodified nanoparticles development.

\section{Research Objectives}

The synthesis of fluorinated-silica-nanoparticles using perfluorooctanoic acid (PFOA) and perfluorononanoic acid (PFNA) as a wettabilty alteration agent were reported for the first time in this paper. The method for synthesizing and characterizing is described in detail. It is believed that his fluorinated nanoparticles can improve the gas productivity by removing the liquid blockage neare wellbore.

\section{Methodology}

Fluorinated nanoparticles were prepared by dispersing $0.02 \mathrm{~g}$ of $\mathrm{SiO}_{2}$ nanoparticles in $10 \mathrm{~mL}$ of ethanol, followed by adding $10 \mathrm{~mL}$ of mixture containing PFOA (0.02 $\mathrm{g})$ and ethanol (10 $\mathrm{mL}$ ) to the solution at room temperature. Then, the solution was sonicated for 30 minutes with temperature at $70{ }^{\circ} \mathrm{C}$, above the melting point of PFOA and PFNA. This temperature is selected so that the fluorochemicals (PFOA and PFNA) could coated the nanoparticles easily above its 


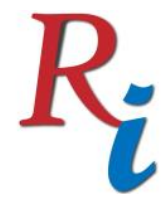

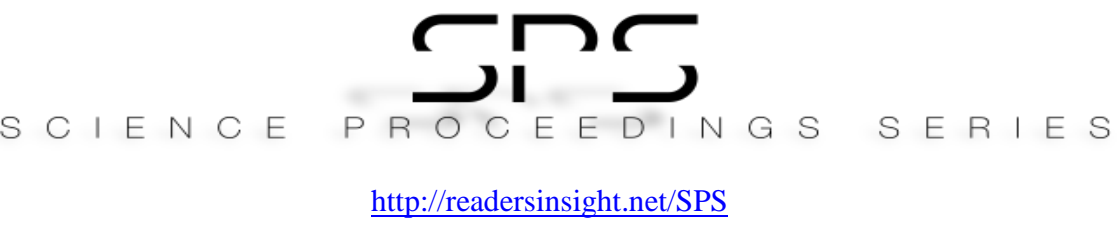

melting point. The experiments above were then repeated using different type of fluorochemicals, i.e. PFNA. Prior to characterization, the nanofluid - which is the coated nanoparticles suspended in ethanol - was then sent to oven at temperature above ethanol boiling point in order to remove any moisture resides with the nanoparticles. The end product of surface-modified nanoparticles after being dried is in a solid form (powder). This powder is then subjected to further characterization such as FTIR, DLS and TGA.

\section{Results}

FTIR spectra of the unmodified nanosilica and the surface-modified nanoparticles is shown in Figure 1. Characterization of unmodified nanosilica and fluorinated nanosilica by DLS is shown in Figure 2. Figure 3 showed the TGA analysis of the pure silica nanoparticles and functionalized nanosilica.

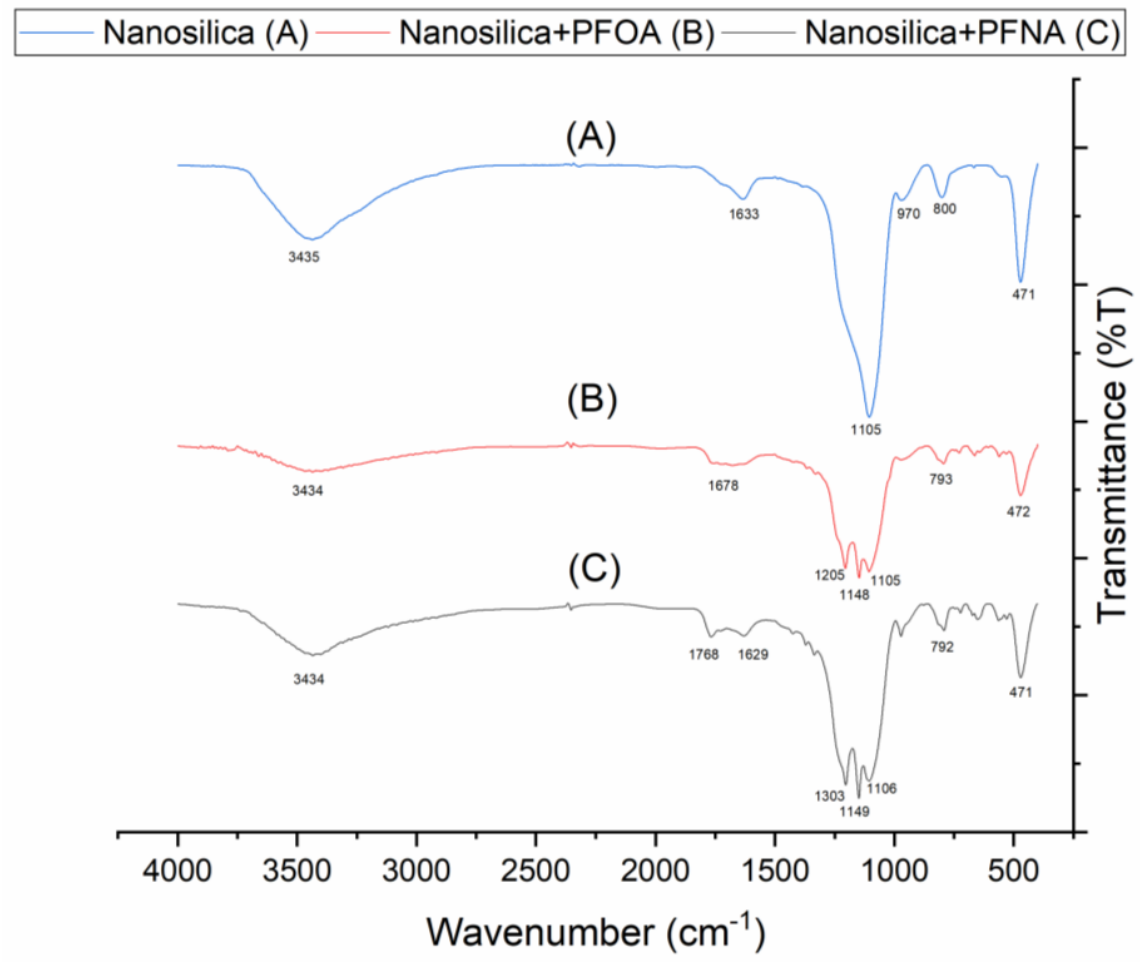

Figure 1: FTIR spectra of (a) unmodified nanosilica; (b) PFOA-modified-nanosilica;

(c) PFNA-modified-nanosilica. 

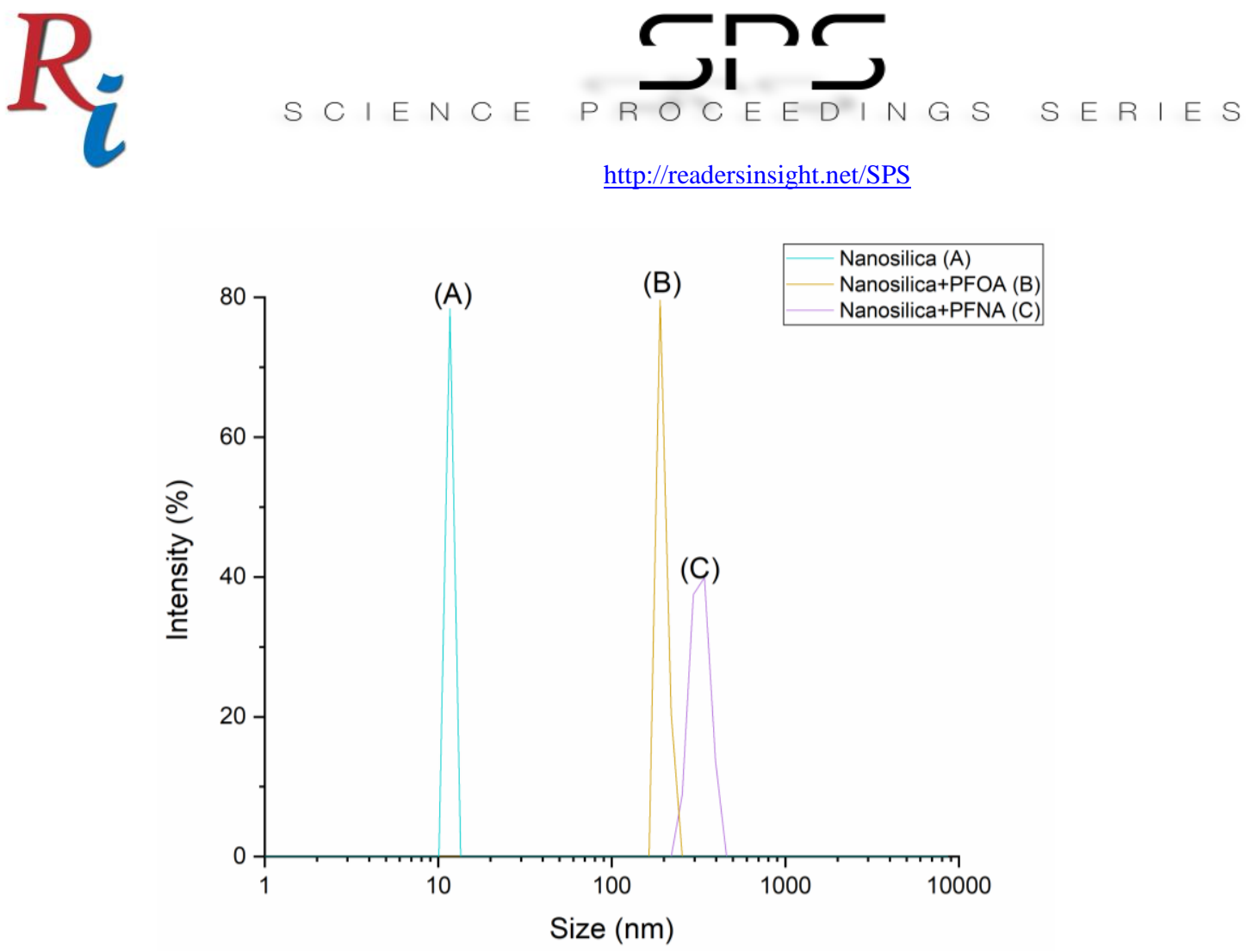

Figure 2: DLS of the unmodified nanosilica and surface-modified nanosilica.

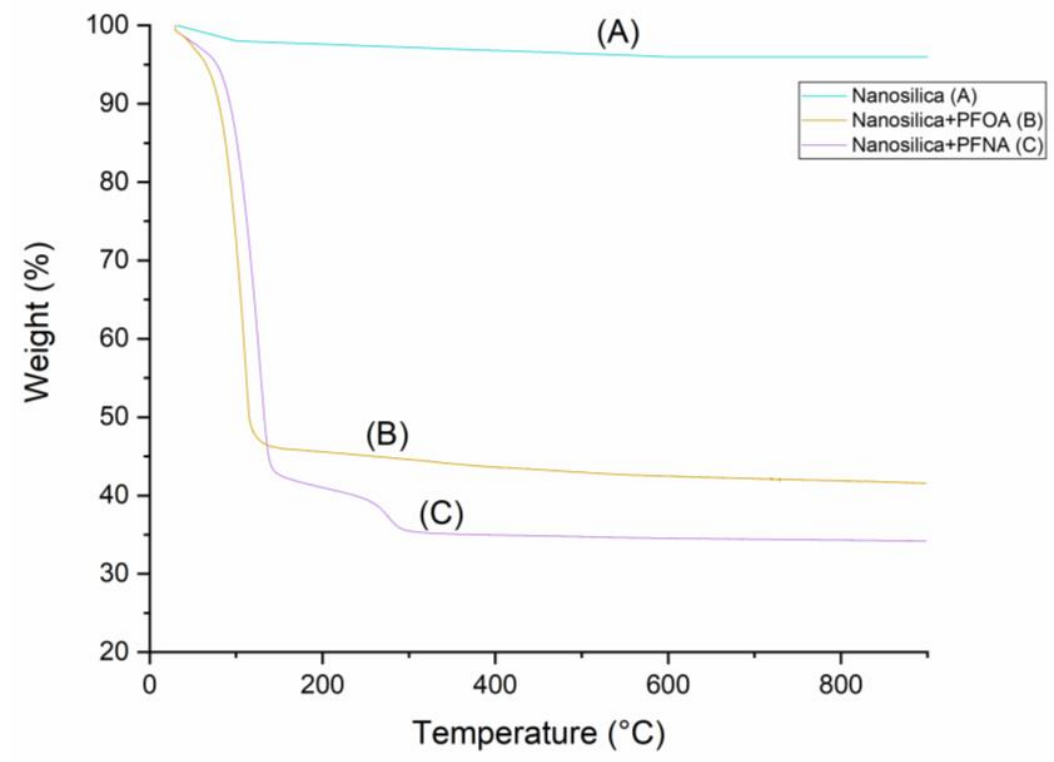

Figure 3: TGA analyses of the unmodified and surface-modified nanosilica.

\section{Findings}

FTIR characterization showed several new peaks formed on the surface-modified nanoparticles compare to the pure nanosilica. This confirmed that a new bond has been formed on the surface of nanoparticles. DLS characterization showed the particles to be approximately $100-400 \mathrm{~nm}$ 


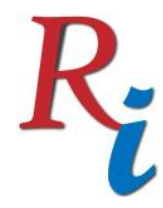

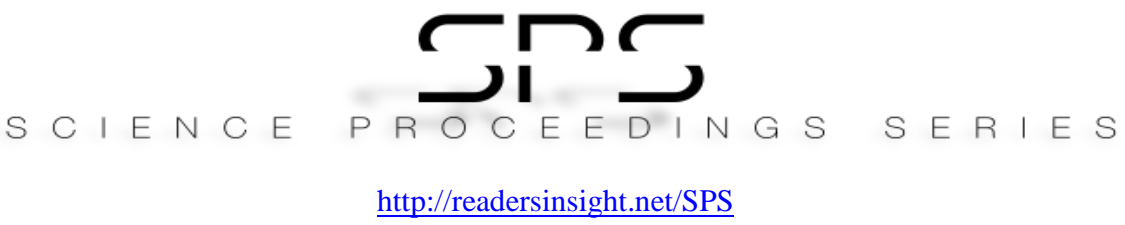

in size and that the uniformity was maintained during the functionalization of the silica nanoparticles. Incremental size between pure nanosilica and surface-modified nanosilica indicated that the surface has been shrouded by the coating agent. TGA characterization, however, showed higher decomposition rate in functionalized nanoparticles compare to unmodified nanosilica. This indicated that the functionalized nanoparticles has thicker coating compare to the unmodified nanosilica.

\section{Acknowledgement}

We would like to thank Universiti Teknologi PETRONAS and Universiti Teknologi Malaysia for providing support and assistance.

\section{REFERENCES}

[1] Ahmadi M, Sharma MM, Pope G, Torres DE, McCulley CA, Linnemeyer H. Chemical Treatment To Mitigate Condensate and Water Blocking in Gas Wells in Carbonate Reservoirs. SPE Production \& Operations. 2011;26(01):67-74.

[2] Bang VSS, Pope GA, Sharma MM, Baran JR. Development of a Successful Chemical Treatment for Gas Wells With Liquid Blocking. SPE Annual Technical Conference and Exhibition: Society of Petroleum Engineers; 2009. p. 124977-.

[3] Li K, Firoozabadi A. Experimental Study of Wettability Alteration to Preferential GasWetting in Porous Media and Its Effects. SPE Reservoir Evaluation \& Engineering. 2000;3(02):139-49.

[4] Tang G-Q, Firoozabadi A. Relative Permeability Modification in Gas/Liquid Systems Through Wettability Alteration to Intermediate Gas Wetting. SPE Reservoir Evaluation \& Engineering. 2002;5(06):427-36.

[5] Zhang S, Jiang G-C, Wang L, Qing W, Guo H-T, Tang X-g, et al. Wettability alteration to intermediate gas-wetting in low-permeability gas-condensate reservoirs. Journal of Petroleum Exploration and Production Technology. 2014;4(3):301-8.

[6] Ganie K, Idris AK, Mohshim DF, Wan Sulaiman WR, Mohd Saaid I, Abdul Malik A. A review on the wettability alteration mechanism in condensate banking removal. Journal of Petroleum Science and Engineering. 2019;183.

[7] Kissa E. Fluorinated surfactants and repellents. 2nd ed. Wilmington, Delaware, USA: Marcel Dekker Inc.; 2001. 